\title{
Ring melanoma of the iris and ciliary body
}

\author{
WOJCIECH OMULECKI, ' MACIEJ PRUSZCZYŃSKI, ${ }^{2}$ AND JANUSZ BOROWSKI ${ }^{3}$ \\ From the 'Department of Ophthalmology, Medical Academy of Lódź, the ${ }^{2}$ Department of Pathological \\ Anatomy, Institute of Pathology, Medical Academy of Lódź, and the ${ }^{3}$ Department of Ophthalmology, Jonscher \\ Municipal Hospital in Lódź, Poland
}

SUMmary The case is described of a tumour of the iris and ciliary body-a ring type melanoma - primarily diagnosed and treated as pigmentary glaucoma.

Malignant melanoma of the anterior part of the uveal tract, spreading round the eyeball, is called ring melanoma. ${ }^{1-x}$ The first case of such a tumour was described by Solomon in 1882 (quoted in Rockwell ${ }^{\circ}$ ).

The growth of a ring melanoma may begin in the anterior part of the ciliary body, in the iris, or in the iridociliary junction. The neoplasm spreads round the major arterial circle of the iris and along the ciliary muscle. Its growth towards the choroid may cause retinal detachment and imitate primary tumour of the choroid. Infiltration of the chamber angle causes secondary glaucoma. Heterochromia or even tuberosity of the affected iris may occur. The tumour spreading along the scleral blood vessels and nerves and along Schlemm's canal causes extrascleral growth, imitating primary melanoma of the bulbar conjunctiva. ${ }^{125}{ }^{24-11}$

According to Rockwell 32 cases of ring melanoma of the ciliary body and iris had been reported up to 1952. ${ }^{6}$ Later on further cases were added. ${ }^{4-4}$

\section{Case report}

A man aged 57 consulted an ophthalmologist in January 1983 complaining of some deterioration of vision in the left eye. Examination revealed visual acuity $6 / 8$ with elevated intraocular pressure. There were a few pigmentary sediments on the corneal endothelium. The iris was blue, its structure normal, with pigment scattered on the surface. On the circumference of the lens initial opacification was observed. The fundus did not show any abnormalities. Gonioscopy showed a wide chamber angle, filled with pigment. Tonography by Grant's method gave 0.05 . The field of vision was normal. The right eye showed amblyopia, visual acuity $2 / 60$, without any other noticeable abnormalities.

Correspondence to Dr W Omulecki, Klinka Chorób Oczu, ul. Kopcińskiego 22, 90-153 Lódź, Poland.
Although the patient had been treated for three months with pilocarpine, timolol, phenylephrine, and acetazolamide, the intraocular pressure oscillated between 28 and $43 \mathrm{mmHg}$. Pigmentary glaucoma was diagnosed and trabeculectomy performed. The post operative course was uneventful and the pressure reduced to normal $(14-17 \mathrm{mmHg})$. During the following seven months the patient had regular examinations, which did not reveal any further abnormalities in the operated eye.

Two months later the patient consulted the ophthalmologist again complaining of the pigmented changes noticed in the operated eye. He was admitted to the clinic with a diagnosis of intraocular malignant melanoma.

Examination showed almost normal visual acuity in the left eye and an intraocular pressure of 14 $\mathrm{mmHg}$. Dispersed, brownish-black subconjunctival nodules grouped together in the medial angle of the eye were visible (Figs. 1, 2, 3). One of the nodules covered the limbus of the cornea at 11 o'clock, and three other nodules were located on the caruncle.

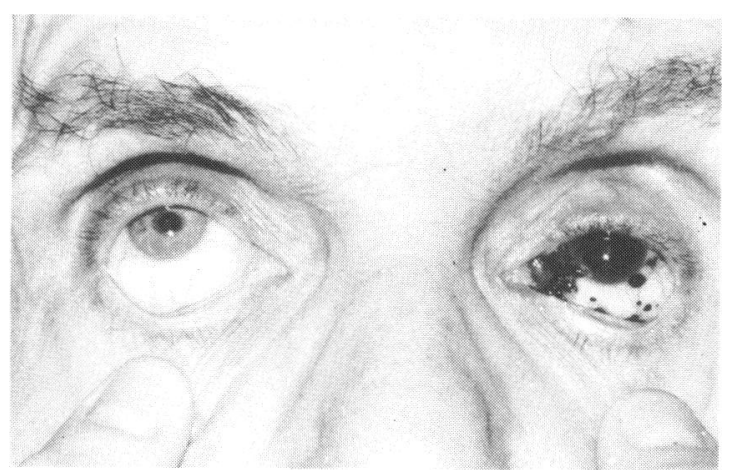

Fig. 1 View of both eyes with hyperpigmented nodules and heterochromia of the iris in the left eye. 


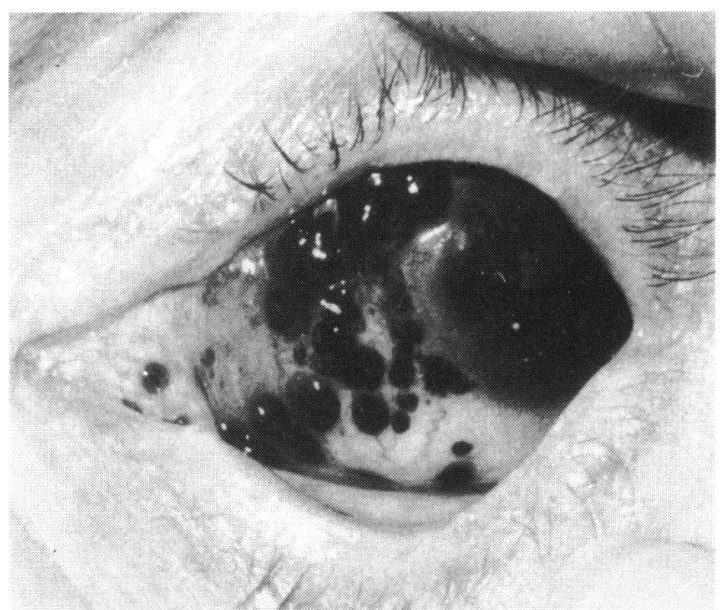

Fig. 2 Numerous, brownish-black nodules varying in size, grouped in the medial angle of the eye. One of the nodules covers the limbus of the cornea.

Brown hyperpigmentation was visible on the conjunctiva and the margin of the lower lid. There were several pigmentary sediments on the corneal endothelium. The colour of the iris had changed to dark brown and its surface was nodular. The postoperative peripheral defect of the iris was two-thirds covered by a pigmented tissue. The lens showed initial opacifications at its periphery, with dispersed pigment on the surface. The optic disc was pale, with typical glaucomatous excavation. Gonioscopy showed a chamber angle of medium width, narrowed in some places and entirely filled with pigment. Scintigraphy with chromium ${ }^{51} \mathrm{Cr}$ labelled bleomycin revealed greater

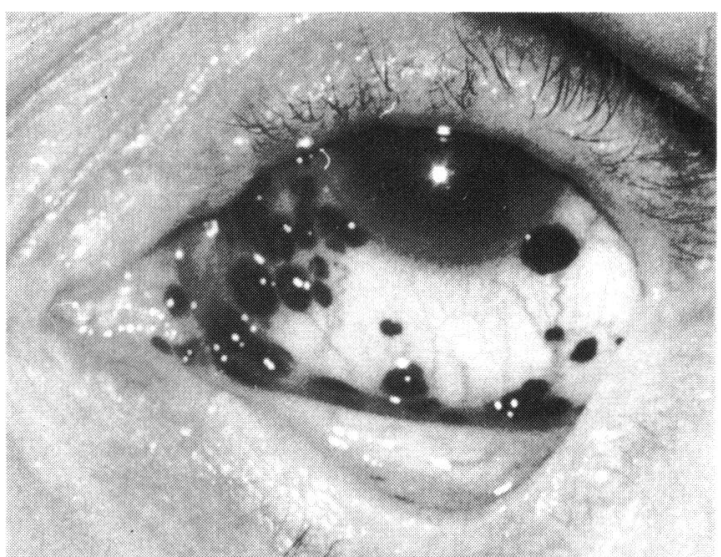

Fig. 3 Nodules in the medial angle and in the lower part of the eyeball.

accumulation of the marker in the left eye. A general medical examination did not show any essential abnormalities, and the results of biochemical tests were unchanged. Radiographs of the thorax and the vertebral column, as well as scintigraphy of the liver and spleen, did not reveal any metastases. Under general anaesthesia the orbit was exenterated.

\section{HISTOLOGICAL EXAMINATION}

The specimen was divided into two parts, embedded in paraffin, and cut in serial sections. Microscopically a malignant neoplasm was seen which infiltrated circumferentially the whole iris and a considerable part of the ciliary body, occupying the chamber angle. It infiltrated the sclera with its vessels, spread-

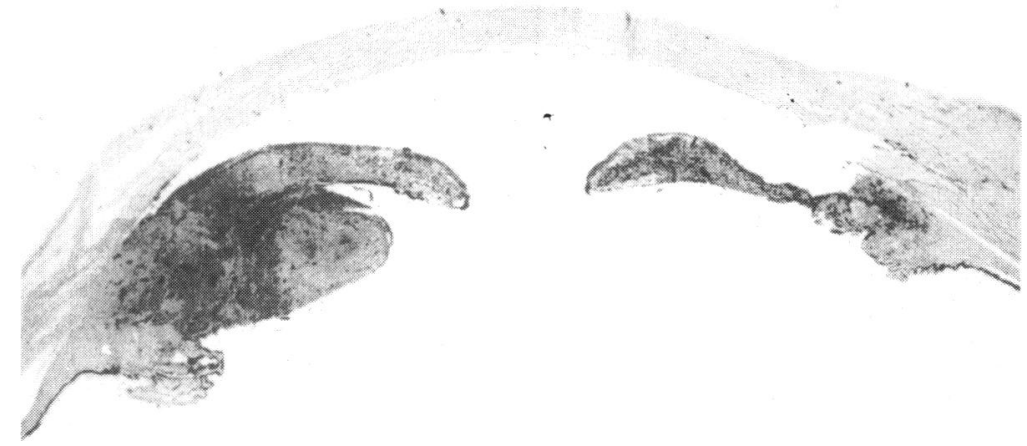

Fig. 4 Malignant melanoma infiltrating circumferentially the iris and ciliary body. 
ing to episcleral tissues and conjunctiva, where numerous subepithelial nodules were formed (Figs. $4,5,6,7,8)$. The tumour cells were spindle-shaped or epithelioid-like, with oval polymorphous nuclei and irregular prominent nucleoli. Numerous cells contained a large amount of melanin. The individual cells or groups of cells were separated by a dense net of reticulin fibres. Posterior structures of the globe, the optic nerve, and soft tissues of the orbit were not infiltrated. The diagnosis was malignant melanoma of the iris and ciliary body (ring type melanoma), of mixed cellular type with a considerable amount of pigment and reticulin fibre. The resection lines were free of neoplastic infiltration.
Fig. 5 and 6 The infiltration of the iris, the base of the ciliary body, and the region of the chamber angle by the melanomatous cells. Spread of the tumour along the communicating vessels in the sclera. (Haematoxylin and eosin, $\times 80)$.

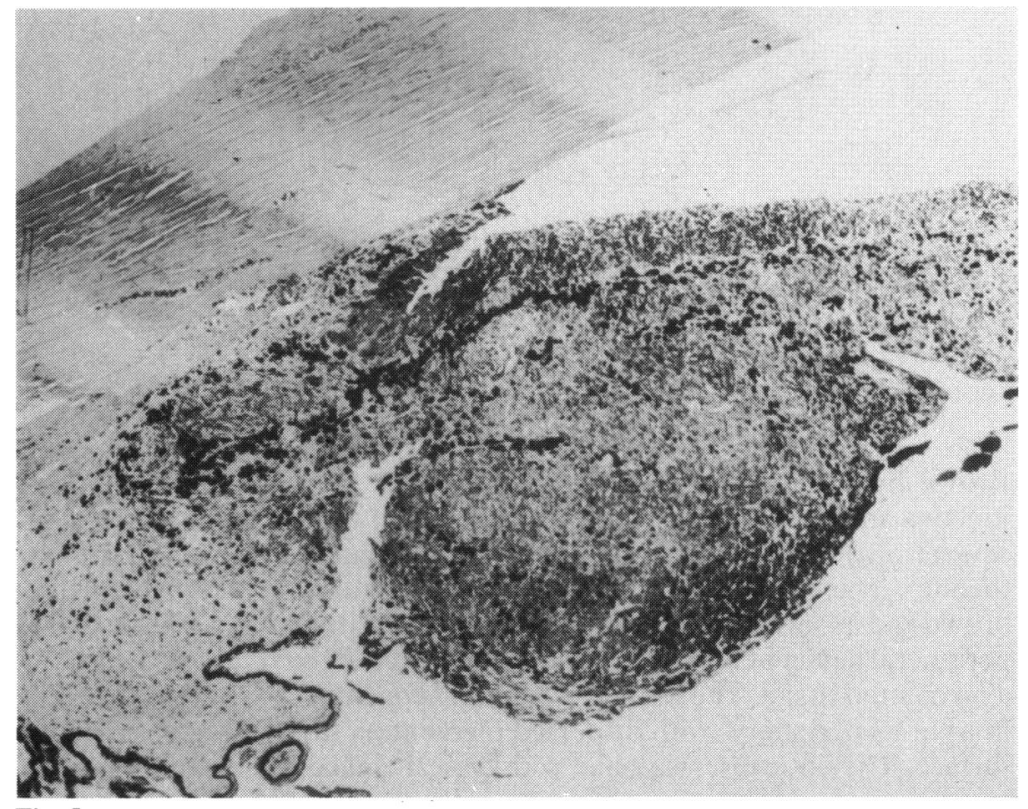

Fig. 5

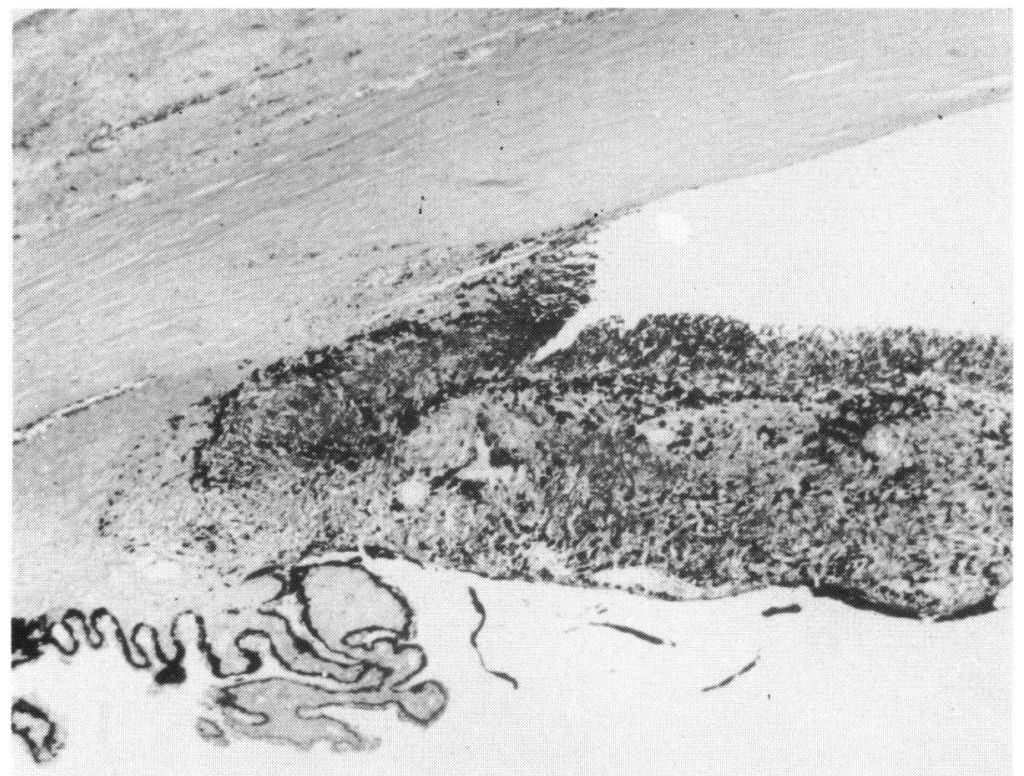

Fig. 6 


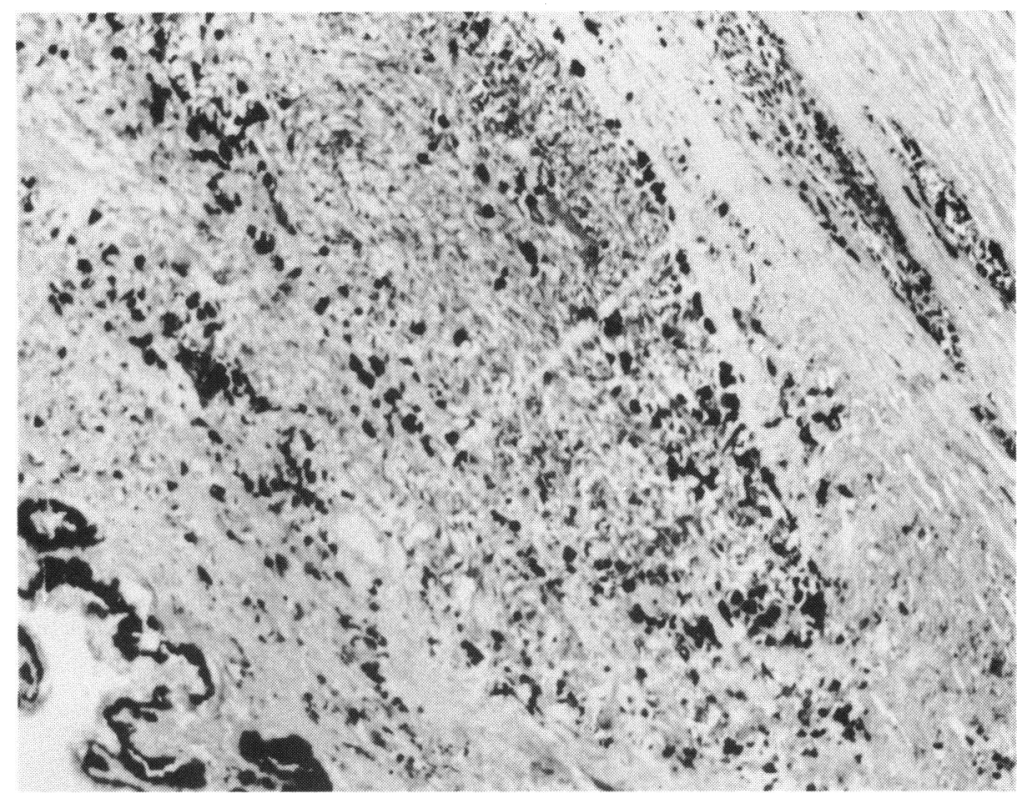

Fig. 7 Solid melanomatous infiltration of the ciliary body and the dissemination of the neoplastic cells within the sclera. (H and $E$, $\times 150)$.

\section{Discussion}

Reports have shown that in cases of ring melanoma the structures of the chamber angle and the outflow canals are almost always invaded, which leads to secondary glaucoma. Increased intraocular pressure may be the first symptom of a tumour, but such cases are frequently misdiagnosed and surgically treated as primary glaucoma, because the attention of an ophthalmologist is drawn to the increased intraocular pressure rather than to the slowly developing hyperpigmentation of the iris. ${ }^{1357} 12$

In our case at first heterochromia was not observed, and gonioscopy did not reveal any signs of the tumour. Consequently pigmentary glaucoma ${ }^{1314}$ was diagnosed and antiglaucomatous surgery performed. Only after some months did the presence of dark nodules under the bulbar conjunctiva and iris heterochromia suggest the dissemination of malignant melanoma.

It should be remembered that ipsilateral glaucoma with even slight hyperpigmentation in the anterior part of the eye should arouse suspicion of melanoma. We believe that histopathological examination of the biopsy specimen removed from the iris during an antiglaucomatous operation would make a correct diagnosis possible.

Our patient was in his sixties, but a considerable

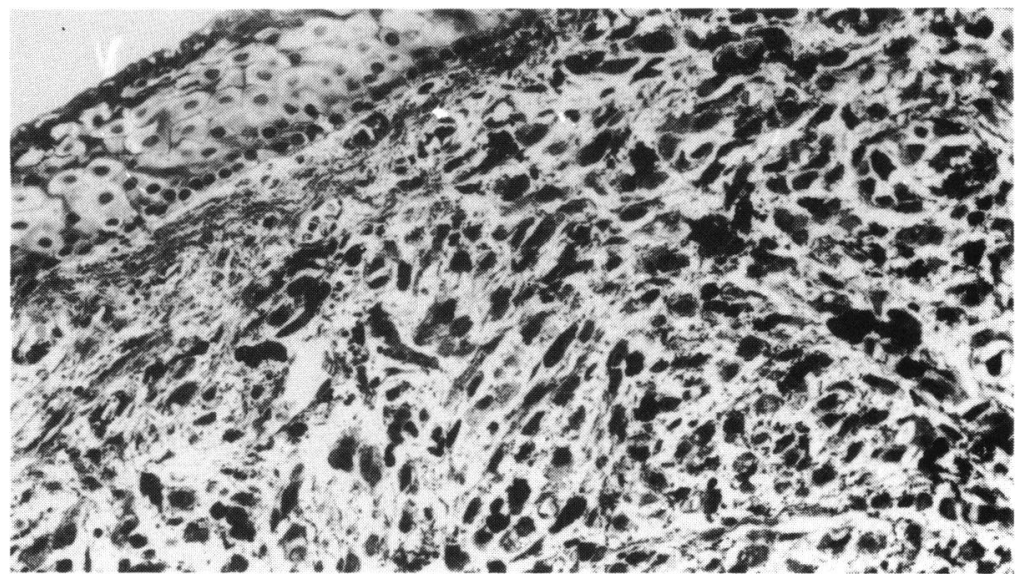

Fig. 8 Malignant melanoma with heavily pigmented cells, infiltrating the conjunctiva and lifting its epithelium. (Hand E, $\times 220)$. 
proportion of ring melanomas have been reported in people in the first two decades of their lives. So it should be kept in mind that youth is not a factor reducing the chance of developing a melanoma of this type. Many authors emphasise that melanomas of the iris, because of the possibility of their early detection and their usually spindle cell structure, have a better prognosis than choroidal melanomas. ${ }^{15}$ However, the prognosis in our patient is doubtful because of subconjunctival dissemination of the tumour and its epithelioid cell component.

\section{References}

1 Duke-Elder S. System of ophthalmology. London: Kimpton, 1977.

2 Hogan MJ, Zimmerman LE. Ophthalmic pathology. Philadelphia: Saunders, 1962.

3 Manschot WA. Ring melanoma. Arch Ophthalmol 1964; 71: 625-32.

4 Perkins ES, Magnus JA. Ring sarcoma of the iris. $\mathrm{Br} J$ Ophthalmol 1961; 45: 821-3.
5 Reese AB. Tumours of the eye. London: Cassel, 1951.

6 Rockwell PA. Annular malignant melanoma of the iris and ciliary body. Am J Ophthalmol 1952; 35: 1806-10.

7 Spoulding AG, Green WR, Font RL. Ring shaped limbal tumor secondary to unrecognized diffuse malignant melanoma of the uvea. Arch Ophthalmol 1967; 77: 76-80.

8 Zygulska-Machowa $\mathrm{H}$. Melanoma annulare malignum iridis et corporis cilliaris. Klin Oczna 1966; 36: 605-7.

9 Sheie HG, Yanoff M. Pseudomelanoma of the ciliary body. Arch Ophthalmol 1967; 77: 81-3.

10 Yanoff M. Pigment spots of the sclera. Arch Ophthalmol 1969; 81: $151-4$.

11 Dunphy EB, Dryja TP, Albert DM, Smith TR. Melanotic tumor of the anterior uvea. Am J Ophthalmol 1978; 86: 680-83.

12 Yanoff $M$. Glaucoma mechanism in ocular malignant melanomas. Am J Ophthalmol 1970; 70: 898-904.

13 Heilmann K, Richardson KT. Glaucoma. Conceptions of a disease: pathogenesis, diagnosis, therapy. Stuttgart: Thieme, 1978.

14 Kolker AE, Hetherington J Jr. Becker-Schaffer's diagnosis and therapy of the glaucomas. St Louis: Mosby, 1976.

15 Zimmerman LE. Types histologiques des tumeurs de l'oeil de ses annexes. Classification histologique international des tumeurs. Geneve: OMS, 1980: 24. 